\title{
CLINICAL MANIFESTATION AND PATHOGENESIS OF NERVOUS SYSTEM INVOLVEMENT IN SEVERE ACUTE RESPIRATORY SYNDROME CORONAVIRUS-2 INFECTION
}

\author{
VALENTINA TJANDRA DEWI ${ }^{1}$, ANAK AGUNG AYU PUTRI LAKSMIDEWI ${ }^{*}$, KETUT AYU SUDIARIANI $^{2}$
}

${ }^{1}$ Department of Neurology, Faculty of Medicine Udayana University, Sanglah General Hospital, Denpasar, Bali, Indonesia. ${ }^{2}$ Department of Neurology, Tabanan General Regional Hospital, Bali, Indonesia. Email: putri_laksmidewi@unud.ac.id

Received: 10 July 2020, Revised and Accepted: 13 August 2020

\section{ABSTRACT}

Severe acute respiratory syndrome coronavirus-2 (SARS-CoV-2) or CoV disease 2019 (COVID-19) infection has spread throughout the world and becomes a global pandemic. Various studies are still ongoing to be able to understand this viral infection in terms of symptomatology, transmission, pathogenesis, its treatment, and prevention. In addition to respiratory symptoms that are commonly reported in SARS-CoV-2 infections, there are many reports of symptoms appearing in other organ systems with one of them being neurological manifestation. The neurological manifestations involve not only the central and peripheral nervous systems but also there was also a suspicion that the potential invasion of SARS-CoV-2 in the nervous system might be able to take part in the occurrence of respiratory failure that is found in patients with COVID-19. The continuity of the study and the awareness of medical personnel from various fields of science must be increased to fight against the COVID-19 pandemic and ensuring optimal treatment for patients.

Keywords: Coronavirus disease-19, Severe acute respiratory syndrome coronavirus-2, Neurological, Nervous, Manifestation

(c) 2020 The Authors. Published by Innovare Academic Sciences Pvt Ltd. This is an open access article under the CC BY license (http://creativecommons. org/licenses/by/4. 0/) DOI: http://dx.doi.org/10.22159/ajpcr.2020.v13i10.39006

\section{INTRODUCTION}

Severe acute respiratory syndrome coronavirus (SARS-CoV-2) or better known as $\mathrm{CoV}$ disease (COVID)-19 infection was first identified in December 2019 in Wuhan city, China. Since this disease was first discovered, in the span of 7 months from December 2019 until July 2020 , this infection has spread rapidly to reach 10 million case findings spread throughout 213 countries and had caused more than 500,000 deaths. The World Health Organization itself has determined COVID-19 infection as a global pandemic since March 11, 2020 [1].

SARS-CoV-2 spreads mainly through droplets or saliva or secretions from the nose when an infected person coughs or sneezes [2,3]. The time between exposures to the onset of symptoms is generally around 5 days but can range from 2 to 14 days. Most patients infected with the COVID-19 virus experience mild-to-moderate respiratory symptoms and can recover without the need for special therapy [4,5]. Older people and patients with underlying or comorbid diseases such as chronic respiratory disease, cardiovascular disease, diabetes mellitus, or cancer are generally at greater risk of developing severe infections and multiorgan failure [6].

In SARS-CoV-2 infection, the most common symptoms are those of the respiratory system, which include fever, coughing, and shortness of breath. Other symptoms that are often found are tiredness, sore throat, digestive symptoms such as abdominal pain and diarrhea, muscle pain, and disruption of the olfactory function. The transmission rate of SARS-CoV-2 infection is very high with wide symptomatology ranging from nonspecific symptoms or mild illness to severe pneumonia accompanied by respiratory failure, septic shock, and death [7]. With the increasing number of cases every day, there were reports of neurological manifestation of COVID-19 infection. In some cases, it had also been found that neurological manifestations could become the first symptom appearing in patients with SARS-CoV-2 infection [6].

Neurological manifestations have been observed in patients infected with COVID-19. Several neurological manifestations reported include acute stroke, impaired consciousness or altered mental status, and skeletal muscle injury [7]. Mao et al. classified the neurological manifestations of COVID-19 into three major groups that consist of central nervous system symptoms, peripheral nervous system symptoms, and skeletal muscle symptoms [7]. Acute cerebrovascular disease including ischemic stroke and cerebral hemorrhage can increase the risk of death, but there is a suspicion that respiratory failure in patients with COVID-19 pneumonia can be influenced by the potential neuroinvasion of SARS-CoV-2 to the respiratory center in the brain stem area [8-12].

Until now, it is still being studied about how SARS-CoV-2 invades the central and peripheral nervous system, both in terms of manifestations of symptoms, etiology, and pathogenesis to therapeutic recommendations that can be given. In an effort to detect COVID-19 cases as early as possible to provide appropriate treatment, every clinician not exclusive to neurologists only must raise awareness in handling cases with neurological symptoms.

\section{INTERACTION OF SARS-COV-2 WITH HOST CELLS}

The genome for SARS-CoV-2 is 29,903 bp single-stranded RNS CoV. Studies that have been conducted show that COVID-19 and SARS$\mathrm{CoV}$ shared the same receptor to invade cells which is angiotensinconverting enzyme 2 (ACE2) [13,14], hence the name SARS-CoV-2.

$\mathrm{CoV}$ particles are covered by envelopes and they are having three proteins on the membrane surface: Spike (S), envelope (E), and membrane (M). The spike (S) protein appears projecting from the viral membrane and resembles a crown, this protein is a key structure of the infectivity and pathogenicity of COVID-19 [15]. COVID-19 attaches to the ACE2 receptor through the spike protein (S). Spikes recognize and bind to receptors on the surface of the host cell and then invade the host cell. Organs that are known able to express ACE2 receptors include lungs, heart, kidneys, intestines, brain, and testes, thus increasing the awareness of the possibilities of becoming the target organs of COVID-19 infection [16].

Studies show that the binding of ACE2 to the ectodomain spike protein of SARS-CoV-2 has 10-20 times higher affinity power than SARS- 
$\mathrm{CoV}$ spike protein. Paired sequences of three CoVs were also being compared and it was found that the spikes protein of the three CoVs was very similar but not identical, this could be the reason why COVID-19 spike protein has a higher affinity in their binding with human ACE2 receptors [17].

Genomic analysis shows that SARS-CoV-2 also belongs to the group of beta-CoV same as Middle East respiratory syndrome (MERS)-CoV and SARS-CoV. SARS-CoV-2 also has a homologous sequence similar to SARS-CoV. Public findings show that COVID-19 has a high similarity of pneumonia pathogenesis as pneumonia caused by SARS-CoV or MERS-CoV $[8,18]$. Most CoVs have a similar viral structure and infection pathway, so the mechanism of infection found in other CoVs might also be applied to explain the mechanism of infection by SARS-CoV-2. At present, the evidence is developing that neurotropism is a common characteristic of CoVs [8,19-21].

\section{MECHANISM OF SARS-COV-2 INVASION TO THE NERVOUS SYSTEM}

Until now, the exact mechanism of COVID-19 invasion to the nervous system is still being studied. However, several studies suspected that at least there are two pathways of the SARS-CoV-2 invasion to the human brain. The postulated pathways are through the retrograde neuronal route and hematogenous route [22-25]

As stated earlier, the human brain is able to express ACE2 receptors which detected along neurons and glial cells, therefore, the brain can be a potential target of COVID-19 infection. The previous studies of SARS$\mathrm{CoV}$ inoculation using mice as the animal model have demonstrated its ability to cause neuronal death in mice. The study tested a model of brain invasion using access through the nasal area near the olfactory epithelium. The ability of this virus to invade and live in neural networks or neurotropism can occur through circulation or transcribial routes in the nose that allows COVID-19 to reach the brain and interact with ACE2 receptors. These theories arise also based on previous research on the spread of SARS-CoV to the brain through the systemic circulation or through the cribriform plate in ethmoid bone [26].

Supporting hematogenous route theory, the COVID-19 virus which circulated in the systemic bloodstream will allow it to reach brain circulation. The slow movement of blood in the microcirculation can be one factor that can facilitate the interaction of S protein from COVID-19 with ACE2 receptors in the capillary endothelium. The release of virus particles through capillary endothelium and damage to the endothelium wall necessitates viral access to the brain [26]. Fatal results of COVID-19 neuroinvasion can come not only from the impact of neuronal damage but also from the rupture of cerebral capillary endothelium that can cause a brain hemorrhage. However, there are also dubious study results regarding SARS-CoV invasion through the hematogenous route, especially in the early phase of infection. Ding et al. stated in their study that almost no SARS-CoV virus particles were detected at non-neuronal cells in the infected brain area [27].

The retrograde neuronal route through the cribriform plate to reach the brain has become a widely reported theory in various studies [28-30]. The cribriform plate lies close to the olfactory bulb allowing the virus to reach and influence the brain. The retrograde neuronal route is supported by the fact that some COVID-19 patients experience hyposmia $[31,32]$. Patients with olfactory disorders or hyposmia in the early stages of COVID-19 should always be thoroughly examined to look for possible involvement of the central nervous system.

Studies of SARS-CoV infections affecting the brain in humans and animals show that the area of the infection is quite heavy in the brain stem. Several types of CoVs are demonstrated to be able to spread through a synapse-connected route to the medulla cardiorespiratory center from the mechanoreceptors and chemoreceptors in the lungs and lower respiratory tract [8]. Other evidence also shows that CoVs can invade peripheral nerve terminals and then gain access to the central nervous system through synapse-connected routes [33]. An experimental study using transgenic mice was carried out by Li $e t$ al. and it was reported that either SARS-CoV or MERS-CoV when given intranasally can enter the brain. The entry of the virus is suspected through the olfactory nerve and then spread rapidly to specific areas in the brain including the thalamus and brain stem [34].

The results of various studies on CoVs show that neuroinvasion is a condition that is quite commonly found in CoVs infection. With the high similarity between SARS-CoV and SARS-CoV-2, it is possible that SARS$\mathrm{CoV}-2$ also has the same neuroinvasion potential [8].

\section{NEUROLOGICAL MANIFESTATIONS OF SARS-COV-2 INFECTION}

Recently, there has been an increase in the reporting cases of neurological manifestations in COVID-19. In one of the largest studies on the neurological manifestations of SARS-CoV-2 conducted by Mao et al. in Wuhan, China, it was found that more than onethird of COVID-19 patients in the study experienced neurological manifestations. Neurological symptoms observed vary which involve the central nervous system, peripheral nervous system, and injury to the skeletal muscle $[35,36]$. Neurological symptoms found in the central nervous system include dizziness, headaches, impaired consciousness, acute cerebrovascular disease, ataxia, and epilepsy. Symptoms of the peripheral nervous system that has been found include smell, taste, and vision disorder, neuralgia [35-39]. Skeletal muscle injury can be found clinically as muscle pain with elevated levels of creatinine kinase (CK) to above $200 \mathrm{U} / \mathrm{L}$ [7].

\section{Central nervous system manifestations of SARS-CoV-2 infection}

The most common manifestations of the central nervous system are dizziness and headache. Central nervous system manifestations are significantly more common in patients with severe COVID-19 infection and could manifest as acute cerebrovascular diseases, including ischemic stroke and cerebral hemorrhage. The severity of COVID-19 is defined using international guidelines for community-acquired pneumonia. Patients in the severe infection category were significantly older than those in the non-severe infection category, while hypertension was also significantly more prevalent in patients with severe infections [7].

The impact of clinical deterioration that can occur due to acute neurological events such as stroke will increase the risk of patient death. It is suspected that the main cause of clinical deterioration in COVID-19 patients is hyperactivation of inflammatory factors that cause inflammatory storms or also known as "cytokine storms" which can be fatal (Fig. 1). Other than that, patients with SARS-CoV-2 infection often experience coagulation system disturbances resulting in abnormalities of D-dimers and platelets. Impaired blood coagulability will increase the risk of cerebrovascular disease (Fig. 1) [40-42].

Many of SARS-CoV-2 patients already have previous cerebrovascular risk factors such as hypertension, diabetes mellitus, hyperlipidemia, smoking, and previous history of stroke (Fig. 1). Besides, some patients also experience an acute ischemic stroke for the $1^{\text {st }}$ time, therefore, medical personnel must pay great attention to the neurological manifestations that can occur. In a study conducted by Mao et al., it was found that in COVID-19 patients who have neurological manifestations, as many as $38 \%$ of patients have at least one previous underlying diseases, such as hypertension, diabetes, cardiovascular disease, and malignancy [7].

Laboratory parameters of patients with severe infections SARS-CoV-2 showed a high inflammatory response, indicated by an increase in white blood cells and neutrophil counts, decreased lymphocyte counts, and increased levels of C-reaction protein compared to patients with non-severe infections. This decrease in lymphocyte count may indicate immunosuppression in severe COVID-19 infection group. Patients with severe infections also generally experience increased D-dimers compared to non-severe infections which indicate consumptive coagulation [7]. D-dimer is the final product of plasma in the degradation of thrombin that is rich in fibrin, with an increase in D-dimer, it can 


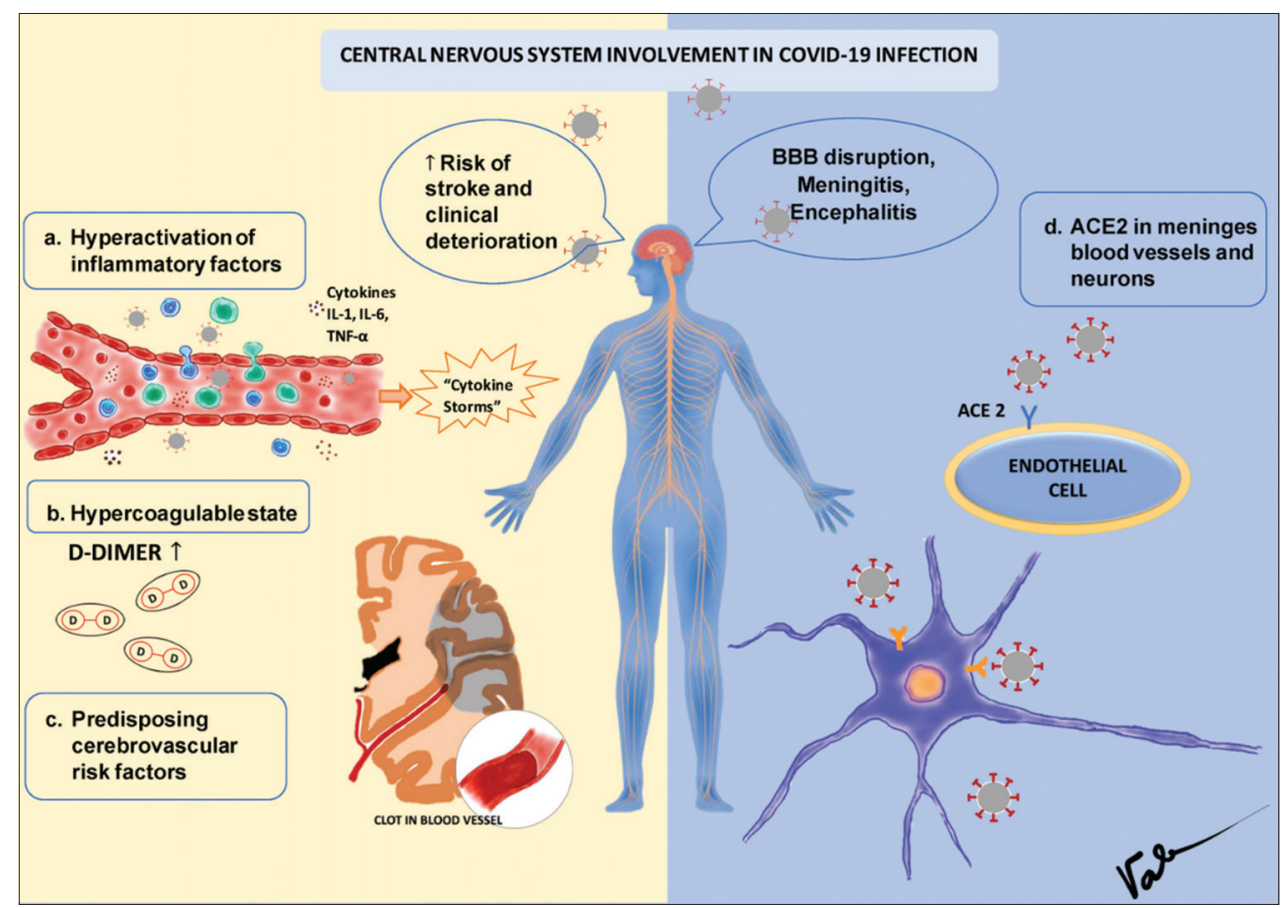

Fig. 1: Central nervous system involvement in coronavirus disease-19 infection

also be one explanation on how acute cerebrovascular events are more common in patients with severe infections.

The proposed mechanisms that provoke ischemic stroke in COVID-19 infection are because of the increased inflammatory response and hypercoagulability conditions [43-46]. Other mechanisms that may also be the etiologies are hypercoagulability conditions from critical illnesses, the occurrence of cardioembolism originating from injury or cardiac disorders due to viruses, the direct role of viral infections, and also hypoxic injuries. The exact mechanism is unknown and still being studied.

In previous SARS-CoV outbreaks, researchers have detected the presence of CoV SARS nucleic acids in a patient's cerebrospinal fluid. SARS-CoV has also been identified in human brain tissue in autopsy [47]. This was also supported by the first reported case of meningitis/encephalitis which was caused by SARS-CoV-2 published by Moriguchi et al. in March 2020. The reported patient initially had symptoms of fever and aches in the body that was not specific, within 9 days of the symptom onset, the patient was taken to the hospital because he was found unconscious, vomiting, and had generalized seizures. Head computed tomography (CT) scan did not portray brain edema, from the lumbar puncture RNA SARS-CoV-2 was detected, while the nasopharyngeal smears showed negative results. Head magnetic resonance imaging (MRI) performed $20 \mathrm{~h}$ after the patient admitted indicated right lateral ventriculitis and encephalitis, especially in the right mesial lobe and hippocampus [48].

Cytokines activation in SARS-CoV-2 infection such as interleukin (IL)-1, IL-6, and tumor necrosis factor-alpha can cause injury to the blood-brain barrier (Fig. 1). It allows cytokines to penetrate the brain parenchyma, especially the mesial temporal lobes as it is having weaker blood-brain barrier $[49,50]$. Central nervous system infections include meningitis or encephalitis could occur since meninges have many blood vessels with high ACE2 receptors. SARS-CoV-2 invasion can damage the blood vessels and cause meninges inflammation. Neuron also presumed to have ACE2 receptors so that it is hypothesized that viral particles can directly invade neurons $[49,51,52]$.

There was also a reported case of acute necrotizing hemorrhagic encephalopathy which is considered to be caused by COVID-19 infection [53]. Acute necrotizing encephalopathy (ANE) is a rare case of encephalopathy and is a rare complication of influenza or other viral infections. ANE occurs associated with intracranial cytokine storms, which have an impact on the disruption of the blood-brain barrier, but without direct viral invasion or parainfectious demyelination [7].

The most common MRI findings of ANE are symmetrical, multifocal lesions with constant thalamus involvement. Other locations that are frequently affected are the brain stem, cerebral white matter, and cerebellum. The lesion will appear hypoattenuating on CT while MRI shows a hyperintense signal on fluid-attenuated inversion recovery $\mathrm{T} 2$ with internal bleeding. Post-contrast images can show a ring of contrast enhancement [54].

Patients infected with SARS-CoV-2 may present with neurological manifestation as their main signs or symptoms, it may be in the forms of impaired consciousness, seizures, and signs and symptoms of intracranial infections. When those aforementioned conditions are found, it is recommended to perform a lumbar puncture to look for the SARS-CoV-2 nucleic acid by the polymerase chain reaction (PCR) method. A head MRI with or without contrast should also be done. For COVID-19 patients with intracranial infections, integrated treatment such as brain edema control, managing and preventing seizures, and management of complications that can occur should be given following standard guidelines.

Peripheral nervous system manifestations of SARS-CoV-2 infection The involvement of the peripheral nervous system that has been reported in COVID-19 infection includes smell, taste, vision disorders, and neuropathy. In the study conducted by Mao et al., the most common peripheral nervous system symptoms found in patients with neurological symptoms were hypogeusia $(5.6 \%)$ and hyposmia (5.1\%) [7]. This frequent discovery of hyposmia supports the widely proposed theory of the retrograde neuronal route used by SARSCoV-2 viral particles to reach the brain (Fig. 2). Recent case reports of hyposmia and acute respiratory failure found in COVID-19 patients need to be further elucidated by isolating the SARS-CoV-2 virus from the area close to the olfactory bulb.

Acute polyneuropathy has been documented in many reports of patients infected with SARS-CoV, MERS-CoV, and SARS-CoV-2 [55]. Twelve cases of Guillain-Barre syndrome (GBS) have also been reported on the current 


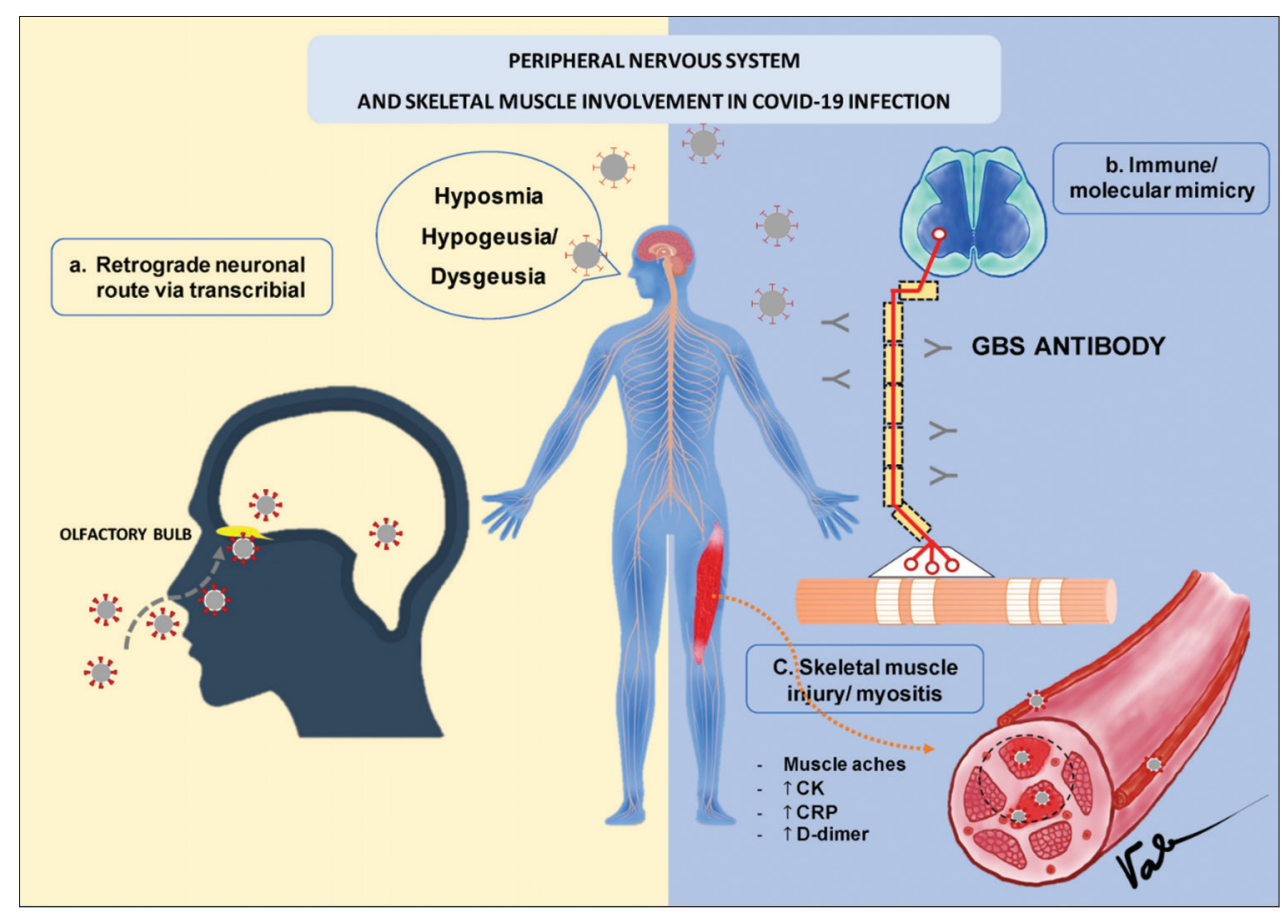

Fig. 2: Peripheral nervous system and skeletal muscle involvement in coronavirus disease-19 infection

evidences of patients with SARS-CoV-2 infection [55-57]. The interval between the onset of viral illness and the development of GBS symptoms was 10 days in approximation. The most common presented symptoms are paresthesia, with progressive and flaccid ascending quadriparesis. Cerebrospinal fluid study showed albumin-cytologic dissociation. Some of them suffered severe illness and required mechanical ventilation. Acute inflammatory demyelinating polyneuropathy subtype was most commonly found [58-60]. Axonal polyneuropathies development in the term of a viral infection suggests that the virus can cause a neural inflammatory reaction through immune mimicry (Fig. 2) or present as part of an inflammatory response syndrome [61]. Mechanism of SARS-CoV-2-related neuropathy needs to be further elucidated.

GBS is believed to occur as a result of molecular mimicry, where there is cross-reactivity from natural immunoglobulin. It is formed in response to viral or bacterial antigen. The specific proteins can be found in myelin, axon, and neuromuscular junction. Furthermore, cytokines during SARS-CoV-2 infection can trigger vasculitis in and around nerve and muscle with or without molecular mimicry [49].

\section{Skeletal muscles injury related to SARS-CoV-2 infection}

Skeletal muscle injuries are quite common in COVID-19 infections. It is defined when a patient experiences pain in the skeletal muscle and there is an increase in CK levels to above $200 \mathrm{U} / \mathrm{L}$ [3]. Besides muscular aches, patients often only experience general weakness. Previously, SARS-CoV has been known to cause inflammation of the heart/ myocardial muscle but during observation, some COVID-19 patients also experience symptoms of skeletal muscle injury (Fig. 2). It is caused by the inflammatory reaction of SARS-CoV-2 infection or can be caused by the direct impact of the virus itself damaging the muscle [47]. Studies showed that in patients with muscle injuries, there were increased C-reactive protein and D-dimer level with higher neutrophil and lower lymphocytes count when compared to COVID-19 patients without muscle injuries. The presence of these abnormalities is a manifestation of increased inflammatory response and blood coagulation [7].

Potential role of neuroinvasion in the respiratory failure of SARS-CoV-2 infection

Several types of CoVs have been demonstrated able to spread through the synapse-connected route to the center of the cardiorespiratory in medulla from the mechanoreceptors and chemoreceptors in the lungs and lower respiratory tract. Experimental studies using transgenic mice show that either SARS-CoV or MERS-CoV administered intranasally can enter the brain through the olfactory nerve. From the olfactory nerve, the virus then spread rapidly to certain brain areas including the thalamus and brain stem. Among the areas of the brain involved, it was found that the brain stem area was heavily infected by SARS-CoV or MERS-CoV [34]. There is also other evidence suggesting that CoVs can invade the terminal part of peripheral nerves then gain access to the central nervous system through the synapse-connected route [33].

In the cases of viral avian bronchitis, trans-synaptic virus transfer was also reported [33]. Intranasal inoculation of the virus in mice causes neural infections in addition to bronchitis or pneumonia. Viral antigens are detected in the brain stem in certain parts including the nucleus of the solitary tract and the ambiguous nucleus. The nucleus of the solitary tract plays the role of receiving sensory information from the mechanoreceptors and chemoreceptors in the lungs and the respiratory tract, where the efferent fibers from the ambiguous nucleus and the solitary tract nucleus provide innervation to the smooth muscles of the airway, glands, and blood vessels. The neuroanatomic interconnection indicates that the death of infected experimental animals could result from dysfunction of the cardiorespiratory center in the brain stem [34].

It is necessary to explore further whether the neuroinvasion potential of SARS-CoV-2 is partially responsible for acute respiratory failure in patients with COVID-19 infection.

\section{RECOMMENDATIONS FOR MEDICAL PERSONNEL AND NEUROLOGISTS}

Besides the respiratory symptoms that primarily appear in patients with COVID-19 infection, various neurological manifestations can also be found or might be the first symptoms that appear. These neurological manifestations can include a variety of central and peripheral nervous system symptoms [7]. If COVID-19 infection is detected too late, patient handling will be hampered, while the risk of transmission of the virus increases [62]. Medical workers and other parties also can be at risk of contracting the virus if they do not apply standard precautions and personal protective equipment, at last, they might also become agents 
of the virus spread [40]. All medical personnel must always wear personal protective equipment by the standard recommendations that have been issued by the government.

Until now, PCR examination for the detection of SARS-CoV-2 nucleic acid is still an essential criterion and becomes the gold standard for diagnosis confirmation. However, its sensitivity is low, and repeated checks are often needed. Patients who are suspected of being clinically infected with SARS-CoV-2 should immediately get proper treatment even if they are still waiting for the results of the PCR test or if the PCR test results are initially negative [40].

Older patients with a background of chronic illnesses are at greater risk of developing impaired consciousness or altered mental status in various acute infection conditions. Some case reports have also reported patients who came to the hospital with encephalopathy and later confirmed SARS-CoV-2 positive [6]. Special attention should be given to cases of patients with altered consciousness.

Patients with COVID-19 infection in the middle age and elderly are the group where stroke more prevalently be found, especially patients with severe infections. Many of these patients already have previous cerebrovascular risk factors such as hypertension, diabetes mellitus, hyperlipidemia, smoking, and stroke history [7]. Some experience acute ischemic stroke for the $1^{\text {st }}$ time. Forming a multidisciplinary team consisting of neurologists, infectious disease specialists and pulmonologists is best considered in managing acute stroke patients when the diagnosis of suspected or confirmed COVID-19 is established. When thrombolytic therapy is indicated, the procedure must follow the protected code stroke protocol [40].

Even when facing the current pandemic situation, patients with hyperacute, acute, or subacute strokes must be treated per normal procedure by sticking to the recent evidence-based guidelines. Treatment time will expectedly increase, considering several adjusted things according to protected code stroke protocol, such as the time allocated for applying personal protective equipment, preparation time, room and equipment decontamination, or sterilization if needed as well as a reduction in the personnel number. It is still recommended to work slowly but careful, get used to pre-brief before every procedure, determine the position and role, limiting the number of team members, avoiding tests or maneuvers that require repeated contact, minimizing the number of people entering, and leaving hospital rooms and also designated safety leader and clinical assessment leader [63,64].

Some limitations might be encountered in managing acute and subacute strokes in the era of the COVID-19 pandemic. Direct discussion of cases between doctors is limited, medical rehabilitation centers and patient care are affected by the lockdown condition and there are service restrictions. Patients with mild stroke symptoms might be afraid and are having more difficulties in seeking medical treatments, also many elderly patients with comorbidities are advised not to visit the red zone areas of COVID-19. The psychological impact has also been felt by various parties. Some solutions that can be applied to keep optimizing patient services include case or scientific discussions by teleconference, optimizing patient and caregiver education, facilitation of medical rehabilitation through online rehab, holding post-stroke clinics, medication top up if possible, and increasing educational videos and websites. In case of patient monitoring whenever possible, it is advised to monitor patients at home using applications, always monitor blood pressure, making a post-stroke checklist, and communicates frequently with patients or caregiver through online.

\section{CONCLUSION}

Case findings and studies have reported neurological manifestations in patients with SARS-CoV-2 infection. These neurological symptoms can accompany respiratory symptoms or other organ symptoms and can even be the presenting symptoms of COVID-19 infection. Every clinician should increase their awareness of the various possible symptoms that can be found in SARS-CoV-2 infection, stay up to date and keep up with the literature. These are important in efforts to establish an early and appropriate diagnosis, to provide optimal treatment, and to reduce the spread of COVID-19 infection.

\section{AUTHORS' CONTRIBUTIONS}

All authors have contributed equally for bringing this review article effectively.

\section{CONFLICTS OF INTEREST}

The author(s) confirm that this article content has no conflicts of interest.

\section{AUTHORS' FUNDING}

We did not receive any funding for the present review.

\section{REFERENCES}

1. WHO. Coronavirus Disease 2019 (COVID-19) Situation Report-94; 2020. Available from: https://www.who.int/docs/default-source/ coronaviruse/situation-reports/20200423-sitrep-94-covid-19. pdf? sfvrsn=b8304bf0 4

2. PAHO, WHO. Epidemiological Update Novel Coronavirus (COVID-19). Geneva: PAHO, WHO; 2020.

3. Sahin AR, Erdogan A, Agaoglu PM, Dineri Y, Cakirci AY, Senel ME, et al. 2019 Novel coronavirus (COVID-19) outbreak: A review of the current literature. Eurasian J Med Oncol 2020;4:1-7.

4. Ministry of Health Infectious Diseases Protocol. Appendix A: Disease-specific Chapters, Diseases Caused by a Novel Coronavirus, Including Severe Acute Respiratory Syndrome (SARS) and Middle East Respiratory Syndrome (MERS). New Delhi: Ministry of Health Infectious Diseases Protocol; 2020

5. Rothana HA, Byrareddy SN. The epidemiology and pathogenesis of coronavirus disease (COVID-19) outbreak. J Autoimmun 2020;109:102433

6. Filatov A, Sharma P, Hindi F, Espinosa PS. Neurological complications of coronavirus disease (COVID-19): Encephalopathy. Cureus 2020;12:e7352.

7. Mao L, Jin H, Wang M, Hu Y, Chen S, He Q, et al. Neurological manifestations of hospitalized with coronavirus disease 2019 in Wuhan, China. JAMA Neurol 2020;77:683-90.

8. Li YC, Bai WZ, Hashikawa T. The neuroinvasive potential of SARS$\mathrm{CoV} 2$ may play a role in the respiratory failure of COVID-19 patients. J Med Virol 2020;92:552-5.

9. Bernstein HG, Dobrowolny H, Keilhoff G, Steiner J. Dipeptidyl peptidase IV, which probably plays important roles in Alzheimer disease (AD) pathology, is upregulated in $\mathrm{AD}$ brain neurons and associates with amyloid plaques. Neurochem Int 2018;114:55-7.

10. Gu J, Gong E, Zhang B, Zheng J, Gao Z, Zhong Y, et al. Multiple organ infection and the pathogenesis of SARS. J Exp Med 2005;202:415-24

11. McCray PB Jr., Pewe L, Wohlford-Lenane C, Hickey M, Manzel L, Shi L, et al. Lethal infection of K18-hACE2 mice infected with severe acute respiratory syndrome coronavirus. J Virol 2007;81:813-21.

12. Khan S, Ali A, Siddique R, Nabi G. Novel coronavirus is putting the whole world on alert. J Hosp Infect 2020;104:252-3.

13. Zhao Y, Zhao Z, Wang Y, Zhou Y, Ma Y, Zuo W. Single-cell RNA expression profiling of ACE2, the putative receptor of Wuhan 2019nCov. BioRxiv 2020;202:756-9.

14. Hamming I, Timens W, Bulthuis ML, Lely AT, Navis G, van Goor H. Tissue distribution of ACE2 protein, the functional receptor for SARS coronavirus: A first step in understanding SARS pathogenesis. J Pathol 2004;203:631-7.

15. Su S, Wong G, Shi W, Liu J, Lai AC, Zhou J, et al. Epidemiology, genetic recombination, and pathogenesis of coronaviruses. Trends Microbiol 2016;24:490-502.

16. Baig AM, Khaleeq A, Ali U, Syeda H. Evidence of the COVID-19 virus targeting the CNS: Tissue distribution, host-virus interaction, and proposed neurotropic mechanisms. ACS Chem Neurosci 2020;11:995-8.

17. Wrapp D, Wang N, Corbett KS, Goldsmith JA, Hsieh CL, Abiona O, et al. Cryo-EM structure of the 2019-nCoV spike in the prefusion conformation. Science 2020;367:1260-3.

18. Hulswit RJ, de Haan CA, Bosch BJ. Coronavirus spike protein and tropism changes. Adv Virus Res 2016;96:29-57.

19. Glass WG, Subbarao K, Murphy B, Murphy PM. Mechanisms of host 
defense following severe acute respiratory syndrome-coronavirus (SARSCoV) pulmonary infection of mice. J Immunol 2004;173:4030-39.

20. Wang D, Hu B, Hu C, Zhu F, Liu X, Zhang J, et al. Clinical characteristics of 138 hospitalized patients with 2019 novel coronavirus-infected pneumonia in Wuhan, China. JAMA 2020;323:1061-9.

21. Chen N, Zhou M, Dong X, Qu J, Gong F, Han Y, et al. Epidemiological and clinical characteristics of 99 cases of 2019 novel coronavirus pneumonia in Wuhan, China: A descriptive study. Lancet 2020;395:507-13.

22. Unni SK, Ruzek D, Chhatbar C, Mishra R, Johri MK, Singh SK. Japanese encephalitis virus: From genome to infectome. Microbes Infect 2011;13:312-21

23. Koyuncu OO, Hogue IB, Enquist LW. Virus infections in the nervous system. Cell Host Microbe 2013;13:379-93.

24. Swanson PA $2^{\text {nd }}$, McGavern DB. Viral diseases of the central nervous system. Curr Opin Virol 2015;11:44-54.

25. Desforges M, Le Coupanec A, Dubeau P, Bourgouin A, Lajoie L, Dube $\mathrm{M}$, et al. Human coronaviruses and other respiratory viruses: Underestimated opportunistic pathogens of the central nervous system? Viruses 2019;12:14.

26. Netland J, Meyerholz DK, Moore S, Cassell M, Perlman S. Severe acute respiratory syndrome coronavirus infection causes neuronal death in the absence of encephalitis in mice transgenic for human ACE2. J Virol 2008;82:7264-75.

27. Ding Y, He L, Zhang Q, Huang Z, Che X, Hou J, et al. Organ distribution of severe acute respiratory syndrome (SARS) associated coronavirus (SARS-CoV) in SARS patients: Implications for pathogenesis and virus transmission pathways. J Pathol 2004;203:622-30.

28. Cardona GC, Pajaro LD, Marzola ID, Villegas YR, Salazar LR. Neurotropism of SARS-cov 2: Mechanisms and manifestations. J Neurol Sci 2020;412:116824.

29. Butowt R, Bilinska K. SARS-cov-2: Olfaction, brain infection, and the urgent need for clinical samples allowing earlier virus detection. ACS Chem Neurosci 2020;11:1200-3

30. Vaira LA, Hopkins C, Salzano G, Petrocelli M, Melis A, Cucurullo M, et al. Olfactory and gustatory function impairment in COVID-19 patients: Italian objective multicenter-study. Head Neck 2020;42:1560-9.

31. Sungnak W, Huang N, Becavin C, Berg M, Queen R, Litvinukova M, et al. SARS-cov-2 entry factors are highly expressed in nasal epithelial cells together with innate immune genes. Nat Med 2020;26:681-7.

32. Xu H, Zhong L, Deng J, Peng J, Dan H, Zeng X, et al. High expression of ACE2 receptor of 2019-ncov on the epithelial cells of oral mucosa. Int J Oral Sci 2020;12:8.

33. Matsuda K, Park CH, Sunden Y, Kimura T, Ochiai K, Kida H, et al. The vagus nerve is one route of transneural invasion for intranasally inoculated influenza a virus in mice. Vet Pathol 2004;41:101-7.

34. Li K, Wohlford-Lenane C, Perlman S, Zhao J, Jewell AK, Reznikov LR, et al. Middle East respiratory syndrome coronavirus causes multiple organ damage and lethal disease in mice transgenic for human dipeptidyl peptidase 4. J Infect Dis 2016;213:712-22

35. Pleasure SJ, Green AJ, Josephson SA. The spectrum of neurologic disease in the severe acute respiratory syndrome coronavirus 2 pandemic infection: Neurologists move to the frontlines. JAMA Neurol 2020;77:679-80

36. Liu K, Pan M, Xiao Z, Xu X. Neurological manifestations of the coronavirus (SARS-cov-2) pandemic 2019-2020. J Neurol Neurosurg Psychiatry 2020;91:669-70.

37. Ogier M, Andeol G, Sagui E, Bo GD. How to detect and track chronic neurologic sequelae of COVID- 19? Use of auditory brainstem responses and neuroimaging for long-term patient follow-up. Brain Behav Immun Health 2020;5:100081.

38. Bridwell R, Long B, Gottlieb M. Neurologic complications of COVID-19. Am J Emerg Med 2020;38:1549.

39. Li Z, Liu T, Yang N, Han D, Mi X, Li Y, et al. Neurological manifestations of patients with COVID-19: Potential routes of SARScov-2 neuroinvasion from the periphery to the brain. Front Med 2020;2020:1-9.

40. Jin H, Hong C, Chen S, Zhou Y, Wang Y, Mao L, et al. Consensus for prevention and management of coronavirus disease 2019 (COVID-19) for neurologists. Stroke Vasc Neurol 2020;5:146-51.

41. Guan W,Ni Z, Hu Y, Liang W, Ou C, He J, et al. Clinical characteristics of coronavirus disease 2019 in China. N Engl J Med 2020;382:18.

42. Diagnosis and Treatment of the Novel Coronavirus Pneumonia (Trial Version 7). National Health Commission of the People's Republic of China; 2020. Available from: http://www.nhc.gov.cn/ yzygj/s7653p/202003/46c9294a7dfe4cef80dc7f5912eb1989/files/ ce3e6945832a438eaae415350a8ce964.Pdf.

43. Heffner KL. Neuroendocrine effects of stress on immunity in the elderly: Implications for inflammatory disease. Immunol Allergy Clin North Am 2011;31:95-108.

44. Spiezia L, Boscolo A, Poletto F, Cerruti L, Tiberio I, Campello E, et al. COVID-19- related severe hypercoagulability in patients admitted to intensive care unit for acute respiratory failure. Thromb Haemost 2020;120:998-1000

45. Jose RJ, Manuel A. COVID-19 cytokine storm: The interplay between inflammation and coagulation. Lancet Respir Med 2020;8:e46-7.

46. Helms J, Kremer S, Merdji H, Clere-Jehl R, Schenck M, Kummerlen C, et al. Neurologic features in severe SARS-cov-2 infection. N Engl J Med 2020;382:2268-70.

47. Lau KK, Yu WC, Chu CM, Lau ST, Sheng B, Yuen KY. Possible central nervous system infection by SARS coronavirus. Emerg Infect Dis 2004;10:342-4.

48. Moriguchi T, Harii N, Goto J, Harada D, Sugarawa H, Takamino J, et al. A first case of meningitis/encephalitis associated with SARSCoronavirus-2. Int J Infect Dis 2020;94:55-8.

49. Fotuhi M, Mian A, Meysami S, Raji CA. Neurobiology of COVID-19. J Alzheimer's Dis 2020;76:3-19.

50. Wu Y, Xu X, Chen Z, Duan J, Hashimoto K, Yang L, et al. Nervous system involvement after infection with COVID-19 and other coronaviruses. Brain Behav Immun 2020;87:18-22.

51. Mehta P, McAuley DF, Brown M, Sanchez E, Tattersall RS, Manson JJ. COVID-19: Consider cytokine storm syndromes and immunosuppression. Lancet 2020;395:1033-4.

52. Xiong M, Liang X, Wei Y. Changes in blood coagulation in patients with severe coronavirus disease 2019 (COVID-19): A meta-analysis. Br J Haematol 2020;189:1050-2.

53. Poyiadji N, Shahin G, Noujaim D, Stone M, Patel S, Griffith B. COVID-19-associated acute hemorrhagic necrotizing encephalopathy: CT and MRI. Radiology 2020;296:E119-20.

54. Wong AM, Simon EM, Zimmerman RA, Wang HS, Toh CH, Ng SH. Acute necrotizing encephalopathy of childhood: Correlation of MR findings and clinical outcome. AJNR 2006;27:1919-23.

55. Montalvan V, Lee J, Bueso T, Toledo JD, Rivas K. Neurological manifestations of COVID-19 and other coronavirus infections: A systematic review. Clin Neurol Neurosurg 2020;194:105921.

56. Gutierrez-Ortiz C, Mendez A, Rodrigo-Rey S, San Pedro-Murillo E, Bermejo-Guerrero L, Gordo-Manas R, et al. Miller fisher syndrome and polyneuritis cranialis in COVID-19. Neurology 2020;95:9619.

57. Toscano G, Palmerini F, Ravaglia S, Ruiz L, Invernizzi P, Cuzzoni MG, et al. Guillain-Barre syndrome associated with SARS-cov-2. N Engl J Med 2020;382:2574-6.

58. Sedaghat Z, Karimi N. Guillain-Barre syndrome associated with COVID-19 infection: A case report. J Clin Neurosci 2020;76:233-5.

59. Otmani HE, El Moutawakil B, Rafai MA, El Benna N, El Kettani C, Soussi M, et al. Covid-19 and Guillain-Barre syndrome: More than a coincidence? Rev Neurol (Paris) 2020;176:518-9.

60. Zhao H, Shen D, Zhou H, Liu J, Chen S, et al. Guillain-Barre syndrome associated with SARS-CoV-2 infection: Causality or coincidence? Lancet Neurol 2020;19:383-4.

61. Tsai LK, Hsieh ST, Chao CC, Chen YC, Lin YH, Chang SC, et al. Neuromuscular disorders in severe acute respiratory syndrome. Arch Neurol 2004;61:1669-73.

62. Diyya AS, Thomas NV. Potential therapeutic avenues for covid-19 therapy. Int J Pharm Pharm Sci 2020;12:11-4.

63. Khosravani H, Rajendram P, Notario L, Chapman MG, Menon BK. Protected code stroke hyperacute stroke management during the coronavirus disease 2019 (COVID-19) pandemic. Stroke 2020;51:1891-5.

64. Kumari VB, Patil SM, Shirahatti PS, Sujay S, Tejaswini M, Ranganatha LV, et al. The current status and prespectives for the emerging pandemic: Covid-19. Int J Pharm Pharm Sci 2020;12:1-10. 